\title{
Behavioral endophenotypes of drug addiction: etiological insights from neuroimaging studies
}

\author{
Bianca Jupp ${ }^{1,2}$ and Jeffrey W. Dalley ${ }^{1,3} *$
}

${ }^{1}$ Behavioral and Clinical Neuroscience Institute, Department of Psychology, University of Cambridge Downing St, Cambridge CB2 3EB, UK, ${ }^{2}$ Florey Institute of Neuroscience and Mental Health, The University of Melbourne, Parkville, Victoria, Australia, ${ }^{3}$ Department of Psychiatry, Addenbrooke's Hospital, University of Cambridge, Cambridge CB2 2QQ, UK.

Running title: Imaging markers of addiction endophenotypes

$\begin{array}{ll}\text { Abstract } & 145 \text { words } \\ \text { Text } & 5841 \text { words } \\ \text { Pages } & 43 \\ \text { Figures } & 1\end{array}$

* Corresponding Author

Dr Jeffrey W. Dalley, Department of Psychology, University of Cambridge, Downing St, Cambridge CB2 3EB, UK. Tel. +44 (0)1223 765 291; Fax. +44 (0)1223 333 564; Email. jwd20@cam.ac.uk 


\begin{abstract}
This article reviews recent advances in the elucidation of neurobehavioral endophenotypes associated with drug addiction made possible by the translational neuroimaging techniques magnetic resonance imaging (MRI) and positron emission tomography (PET). Increasingly, these non-invasive imaging approaches have been the catalyst for advancing our understanding of the etiology of drug addiction as a brain disorder involving complex interactions between predisposing behavioral traits, environmental influences and neural perturbations arising from the chronic abuse of licit and illicit drugs. In this article we discuss the causal role of trait markers associated with impulsivity and novelty-/sensation-seeking in speeding the development of compulsive drug administration and in facilitating relapse. We also discuss the striking convergence of imaging findings from these behavioural traits and addiction in rats, monkeys and humans with a focus on biomarkers of dopamine neurotransmission, and highlight areas where further research is needed to disambiguate underlying causal mechanisms.
\end{abstract}




\title{
Behavioral endophenotypes of drug addiction: etiological insights from neuroimaging studies
}

\author{
Bianca Jupp $^{1,2}$ and Jeffrey W. Dalley ${ }^{1,3 *}$
}

\begin{abstract}
${ }^{1}$ Behavioral and Clinical Neuroscience Institute, Department of Psychology, University of Cambridge Downing St, Cambridge CB2 3EB, UK, ${ }^{2}$ Florey Institute of Neuroscience and Mental Health, The University of Melbourne, Parkville, Victoria, Australia, ${ }^{3}$ Department of Psychiatry, Addenbrooke's Hospital, University of Cambridge, Cambridge CB2 2QQ, UK.
\end{abstract}

Running title: Imaging markers of addiction endophenotypes

$\begin{array}{ll}\text { Abstract } & 145 \text { words } \\ \text { Text } & 5841 \text { words } \\ \text { Pages } & 43 \\ \text { Figures } & 1\end{array}$

* Corresponding Author

Dr Jeffrey W. Dalley, Department of Psychology, University of Cambridge, Downing St, Cambridge CB2 3EB, UK. Tel. +44 (0)1223 765 291; Fax. +44 (0)1223 333 564; Email. jwd20@cam.ac.uk 


\begin{abstract}
This article reviews recent advances in the elucidation of neurobehavioral endophenotypes associated with drug addiction made possible by the translational neuroimaging techniques magnetic resonance imaging (MRI) and positron emission tomography (PET). Increasingly, these non-invasive imaging approaches have been the catalyst for advancing our understanding of the etiology of drug addiction as a brain disorder involving complex interactions between pre-disposing behavioral traits, environmental influences and neural perturbations arising from the chronic abuse of licit and illicit drugs. In this article we discuss the causal role of trait markers associated with impulsivity and novelty-/sensation-seeking in speeding the development of compulsive drug administration and in facilitating relapse. We also discuss the striking convergence of imaging findings from these behavioural traits and addiction in rats, monkeys and humans with a focus on biomarkers of dopamine neurotransmission, and highlight areas where further research is needed to disambiguate underlying causal mechanisms.
\end{abstract}

Keywords: Substance use disorder; impulsivity, sensation/novelty-seeking, PET, MRI, striatum; prefrontal cortex 


\subsection{Introduction}

The worldwide extent of drug use is estimated at 3.4 billion drug users and accounts for over $12 \%$ of all deaths each year (WHO, 2012). However, despite the high prevalence of drug use, fewer than $20 \%$ of drug users lose control over their drug intake and develop clinical signs of addiction (Waldorf et al., 1991). The intricate interplay of multiple genetic and environmental factors which potentially determine an individual's susceptibility to the development of addiction provides a significant challenge to understanding the etiological mechanisms of this disorder (Kreek et al., 2012; Uhl, 2006; Wong and Schumann, 2008). However, one approach that has proved fruitful in recent years has been the investigation of behavioral traits known to pre-dispose individuals to addiction (reviewed in (Meyer-Lindenberg and Weinberger, 2006; Nader et al., 2012; Robbins et al., 2012). Such traits include impulsivity and novelty/sensation-seeking (Ersche et al., 2012a; Ersche et al., 2010; Kreek et al., 2005; Nigg et al., 2006; Verdejo-Garcia et al., 2008) and likely express causally-relevant neurobiological markers of the addiction syndrome (Dalley et al., 2011; Flagel et al., 2009; Piazza et al., 1998).

Neuroimaging approaches such as magnetic resonance imaging (MRI) and positron emission tomography (PET) have had a major impact on the elucidation of biomarkers associated with addiction, impulsivity, and novelty/sensation-seeking (e.g. (Parvaz et al., 2011; Soloff et al., 2003; Whelan et al., 2012)) and, importantly, have revealed significant overlaps in candidate markers between addiction, sensation-seeking and impulsivity and disorders encompassing these behaivoural traits such as attention deficit hyperactivity disorder (ADHD) (e.g. (Frodl, 2010)) a prototypical disorder of impulsivity ((Sonuga-Barke, 2002). However, due to ethical and interpretative constraints, it has not been possible to unambiguously determine causal relationships between impulsivity, novelty/sensationseeking and addiction in humans (Rogers and Robbins, 2001). Experimental animal models 
overcome these limitations by enabling the pre-morbid assessment of behavioral traits and underlying neurobiological mechanisms, together with longitudinal scanning prior to and following drug exposure. Consequently, imaging studies that use clinically-relevant animal models of addiction have the potential to establish causal markers that can be readily translated to human addiction. Here we review converging evidence from pre-clinical and clinical neuroimaging studies on the neurobiological basis of impulsivity and sensation/novelty-seeking and discuss the relevance of these studies for the etiology of addiction.

\subsection{Impulsivity and novelty/sensation-seeking: behavioral endophenotypes predicting} risk for addiction

The behavioral traits of impulsivity and novelty/sensation-seeking have been widely associated with addiction to a broad range of drugs, including stimulants (Moeller et al., 2002; Semple et al., 2005), opiates (Madden et al., 1997; Maremmani et al., 2009), alcohol (Petry, 2001) and tobacco (Bickel et al., 1999). Significantly, the expression of these traits varies throughout the lifespan (e.g. enhanced impulsivity and sensation-seeking is observed during adolescence (Arnett, 1992; Spear, 2000) a period which is also associated with enhanced drug use and addiction) and during different stages of the addiction cycle (e.g. drug use increases impulsivity (Kreek et al., 2005), which may in turn promote continued use). Thus, these traits have potential to contribute both to the etiology and ontogenesis of addiction, a notion strongly supported by evidence that novelty/sensationseeking and impulsivity predict risk for addiction (Belin and Deroche-Gamonet, 2012; Blanchard et al., 2009; Verdejo-Garcia et al., 2008), rates of relapse (Muller et al., 2008) and treatment retention (Moeller et al., 2001; Patkar et al., 2004). However, it is unclear how in neural terms these behavioral traits promote and/or interact with repeated drug use to 
accelerate the emergence of compulsive drug seeking and taking in humans. This remains a major challenge for future research.

\subsection{Impulsivity}

Impulsivity is normally defined as a predisposition for premature, poorly planned, and unduly risky actions (Daruma and Barnes, 1993). Recent theoretical accounts broadly agree that impulsivity consists of at least two major components, motor disinhibition (impulsive action) and impulsive decision-making (impulsive choice), and involve separate but partly overlapping neural mechanisms (Evenden, 1999). Enhanced impulsive action, as defined by laboratory-based measures of performance on the Go/No-Go and stop signal reaction time tasks is often reported in alcoholics (Noel et al., 2007), and long-term abusers of cocaine (Fillmore and Rush, 2002; Hester and Garavan, 2004), and methamphetamine (Monterosso et al., 2005). Additionally, opiate-dependent individuals (Kirby and Petry, 2004), alcoholics (Petry, 2001), stimulant abusers (Kirby and Petry, 2004; Monterosso et al., 2007) and cigarette smokers (Bickel et al., 1999) show increased impulsive choice as indexed by steeper discounting rates for delayed monetary incentives (known as delay discounting). However, it is uncertain whether the co-expression of impulsivity in drug addicts reflects a predisposing trait, a consequence of repeated drug use, or both. Thus, whilst drug use has been shown to increase levels of impulsivity in humans (de Wit, 2009) there is evidence that some forms of impulsivity are actually reduced by drug use (Garavan et al., 2008). Prospective studies in children have found that high levels of impulsivity predicts the initiation of smoking in adolescents (Audrain-McGovern et al., 2009) and populations at risk for the development of addiction demonstrate increased levels of impulsivity, including clinical diagnoses of ADHD and pathological gambling (Verdejo-Garcia et al., 2008). Indeed, increased levels of impulsivity are present in non-drug abusing siblings of dependent individuals; thereby 
suggesting that impulsivity may be an endophenotypic marker (i.e. a behavioral phenotype with an underlying genetic basis) for risk for addiction (Ersche et al., 2012a; Ersche et al., 2012b; Ersche et al., 2010).

Studies in rodents strongly support a causal link between impulsivity and addictionrelated behaviors, although this relationship appears to depend on the particular sub-type of impulsivity (impulsive action versus impulsive choice) and drug class. Rats selected for high levels of impulsive action as measured by enhanced premature responding on the five choice serial reaction time task (Robbins, 2002) demonstrate increased rates of cocaine (Dalley et al., 2007), nicotine (Diergaarde et al., 2008), alcohol (Radwanska and Kaczmarek, 2012) and methylphenidate (Marusich and Bardo, 2009), but not heroin (McNamara et al., 2010) self-administration. These animals additionally show enhanced conditioned place preference to amphetamine (Yates et al., 2012) and have a higher propensity to develop compulsive cocaine self-administration (i.e. enhanced motivation to self-administer on a progressive ratio schedule, persistent non-reinforced responding, resistance to punishment-induced suppression of responding for drug) (Belin et al., 2008) and relapse to cocaine (Economidou et al., 2009) and 3,4-methylenedioxymethamphetamine (MDMA) (Bird and Schenk, 2012) seeking. Impulsive choice has been shown to predict increased alcohol (Oberlin and Grahame, 2009; Poulos et al., 1995) and nicotine (Diergaarde et al., 2008) administration, as well as resistance to extinction and enhanced relapse propensity to nicotine (Diergaarde et al., 2008) and cocaine (Broos et al., 2012). However, there are conflicting findings regarding the relationship between impulsive choice and consumption of cocaine and opiates with studies both supporting (Anker et al., 2009; Garcia-Lecumberri et al., 2011) and refuting (Broos et al., 2012; Schippers et al., 2012) this association. While these findings are perhaps surprising given that heroin and cocaine addicts show delaydiscounting impulsivity (Kirby and Petry, 2004), it is possible that these clinical observations, 
as suggested previously, reflect the effects of chronic drug use on neural substrates underpinning impulse control. Consistent with this hypothesis, both heroin (Schippers et al., 2012) and cocaine (Mendez et al., 2010; Paine et al., 2003; Roesch et al., 2007; Winstanley et al., 2009) exposure increases impulsivity in non-impulsive animals.

\subsection{Novelty/sensation-seeking}

Novelty/sensation-seeking is defined as a tendency to pursue novel and intense emotional experiences (Zukerman, 1979). Like impulsivity, novelty/sensation-seeking represents a multifaceted behavioral construct and can be divided into a number of dimensions related to novelty-seeking, novelty-preference and other behavioral facets including risk-taking, harm avoidance and thrill-seeking, and are reflected as such in the various questionnaire based assays of this behavior (Arnett, 1994; Whohlwill, 1984). Throughout this review, we have chosen to refer to sensation-seeking and novelty-seeking interchangeably to more easily inter-relate basic and clinical research. Work over many years has yielded unequivocal evidence that these personality traits co-exist in individuals with substance dependence (Gerra et al., 2004; Hittner and Swickert, 2006; Noel et al., 2011). Further, novelty/sensationseeking predicts risk for the initiation of drug use (Nees et al., 2012; Sargent et al., 2010; Spillane et al., 2012; Stephenson and Helme, 2006) and is present in individuals at risk for developing substance dependence, including problem gamblers (Fortune and Goodie, 2010) and those with genetic polymorphisms known to confer addiction risk (e.g. the serotonin transporter (Pascual et al., 2007)).

There is some debate, however, whether novelty/sensation-seeking truly represents an endophenotype of addiction risk. Recent studies by Ersche and colleagues found that sensation-seeking was not present in the non-affected siblings of drug addicts (Ersche et al., 2010). However, sensation-seeking was present in individuals who regularly used drugs but 
were able to maintain control over their drug use (Ersche et al., 2012a). These findings suggest that the relationship between sensation-seeking and dependence may not lie in a shared genetic risk for the development of drug addiction, but instead may reflect the consequences of repeated drug use and/or predisposition to drug use and experimentation. The latter possibility is consistent with findings from the primary animal model of sensationseeking, namely enhanced locomotor activity in a novel, inescapable environment (high responders, 'HR', (Piazza et al., 1989) reviewed in (Blanchard et al., 2009)). HR animals typically show an enhanced propensity to self-administer stimulant drugs (Belin et al., 2008; Marinelli and White, 2000; Piazza et al., 1989) but are less likely to develop compulsive cocaine self-administration than highly impulsive rats (Belin et al., 2008). Selectively-bred HR rats are also more likely to assign salience to reward predictive cues, known as 'sign tracking' behavior (Flagel et al., 2010), which has also been shown to motivate cocaine selfadministration (Saunders and Robinson, 2010). Further, sign-tracking behavior has been demonstrated to relate to enhanced novelty preference and in turn to elevated levels of cocaine self-administration (Beckmann et al., 2011).

Sensation-seekers also exhibit impaired reward processing, expressed as an enhanced sensitivity to the reinforcing effects of psychostimulant drugs (Hutchison et al., 1999; Stoops et al., 2007) and physiological reactions to alcohol (Brunelle et al., 2004). Similarly, HR rats show enhanced locomotor reactivity to cocaine (Hooks et al., 1991), self-administer psychostimulants at doses that are not reinforcing in low responder rats (Marinelli and White, 2000; Piazza et al., 1990) and maintain higher levels of operant responding for alcohol (Nadal et al., 2002), cocaine (Piazza et al., 2000) and opiates (Ambrosio et al., 1995). HR rats also exhibit enhanced striatal dopamine (DA) release following exposure to reward predictive cues (Flagel et al., 2011). Such behavior suggests common underlying impairments in 
reward processing, which may underlie the increased propensity of sensation-seekers to initiate and maintain drug use.

The contribution of sensation/novelty-seeking to risk for drug addiction is unclear but may depend, in part on interactions with impulsivity. A recent study found that individuals demonstrating high levels of drug intake, but nevertheless were able to maintain control over their drug use, were sensation-seekers but were not impulsive. However, by contrast, both sensation-seeking and impulsivity traits were present in addicts (Ersche et al., 2012a). Further, non-drug using siblings of addicts were found to be impulsive but were not sensation-seekers (Ersche et al., 2010). These findings suggest that both impulsivity and sensation-seeking traits may interact to drive risk for addiction. In keeping with this, rats impulsive on the five-choice serial reaction time task, which demonstrate drug use modeling addiction (Jupp et al., 2013), fail to show a heightened response to novelty (Dalley et al., 2007; Molander et al., 2011). However, there is evidence for enhanced levels of novelty preference in these (Molander et al., 2011) and other strains of impulsive rats (e.g. the Roman High Avoidance rat (Giorgi et al., 2007). Interestingly, animals showing enhanced levels of novelty preference also developed compulsive cocaine self-administration, indicative of a key aspect of addiction (Belin et al., 2011), although levels of impulsivity prior to drug exposure were not assessed in these animals.

\subsection{Neuroimaging studies of impulsivity and novelty/sensation-seeking}

The evidence reviewed above indicates a clear link between the behavioral traits of impulsivity and novelty/sensation-seeking, the initiation and maintenance of drug intake, and the development of addiction. On the basis of these relationships, an understanding of the neurobiological mechanisms underlying these behavioral traits might inform how these in turn confer risk for addiction. Neuroimaging studies provide a powerful approach to 
investigate the neurobiological substrates mediating such behavioral traits as they offer a means to directly correlate individual variation in behavior with markers of neuronal structure and function. These markers often reflect individual differences in genetic, molecular and cellular processes, and thus can provide valuable insight into the biological origin of complex behavioral traits (Hariri, 2009).

\subsection{Neural correlates of impulsivity}

MRI studies have revealed striking regional variations in brain structure, connectivity, and task-related activation in individuals expressing high levels of impulsivity. In general this research has shown high concordance with findings in animal models of impulsivity (Dalley et al., 2008), and in individuals with specific brain lesions that show enhanced measures of impulsivity (Aron, 2007). This work has consistently highlighted reduced grey matter volume and cortical thickness of the orbitofrontal cortex (OFC) and anterior cingulate cortex (ACC) as markers of impulsivity in humans (Cho et al., 2012; Matsuo et al., 2009; Schilling et al., 2012). In other studies, delay-discounting impulsivity was coupled with morphological abnormalities in the hippocampus and prefrontal cortex (Yu, 2012), and with reduced integrity of fronto-striatal fiber tracts (Konrad et al., 2010; Peper et al., 2012). Notably, impulsivity was also associated with volumetric changes in the frontal lobes of individuals with borderline personality disorder (Sala et al., 2011), bipolar disorder (Matsuo et al., 2009), Parkinson's disease (O'Callaghan et al., 2012) and schizophrenia (Kumari et al., 2009). Additionally, ventral striatal volume negatively correlated with measures of impulsivity in healthy subjects (Cho et al., 2012), suicide attempters (Dombrovski et al., 2012), and individuals with ADHD (Carmona et al., 2009).

Other studies indicate that impulsivity is associated with reduced functional connectivity between medial and lateral regions of the prefrontal cortex and subcortical 
reward structures including the ventral striatum and amygdala (Davis et al., 2012; Schmaal et al., 2012). Further, prefrontal cortical metabolism has been shown to negatively correlate with measures of impulsivity in suicide attempters and patients with borderline personality disorder (Oquendo et al., 2003; Soloff et al., 2003). Impulsive individuals further show reduced activation in the anterior insula and middle frontal cortex during active response inhibition (Farr et al., 2012). Similarly, activation in the ACC was found to correlate inversely with measures of impulsivity in a Go/No-Go task (Liu et al., 2012).

Much previous research indicates that reward-related activity in cortico-striatal circuitry is impaired in impulsive individuals. Questionnaire-based measures of delaydiscounting impulsivity correlated positively with activation in dorsal and ventro-lateral regions of the prefrontal cortex (Hinvest et al., 2011; Sripada et al., 2011), consistent with a postulated role of these regions in salience encoding (Ernst and Paulus, 2005). Impulsive individuals also showed increased ventral striatal activity during performance of a monetary delay-discounting task (Hariri et al., 2006), a finding that may be relevant to divergent patterns of activation within the ventral striatum and amygdala reported in impulsive subjects following win and near-win outcomes during a gambling task (Shao et al., 2013). Thus, the subjective value of wins and emotional responses to near-wins may be enhanced in impulsive individuals. Impulsive individuals also show altered reactivity related to reward value following delays. Specifically, impulsivity correlated with a reduction in ventral striatal activation in relation to the magnitude of future rewards during the delay period (Ballard and Knutson, 2009; Ripke et al., 2012). This prominent effect may underlie the preference of impulsive individuals for immediate, small-magnitude rewards. Interestingly, the relationship between ventral striatal reward reactivity and delay discounting was opposite in individuals with ADHD (Hommer et al., 2011; Strohle et al., 2008; Wilbertz et al., 2012), a difference 
postulated to reflect abnormal reward processing by the OFC in ADHD patients (Wilbertz et al., 2012).

\subsection{Neurochemical correlates of impulsivity}

Given the prominent role of DA in modulating the striatal networks (reviewed in (Onn et al., 2000)) and the central role of this neurotransmitter in addiction and ADHD (e.g. (Kalivas and Volkow, 2005; Solanto, 2002; Volkow et al., 2009)), the majority of PET and SPECT studies have unsurprisingly focused on the brain DA systems. Indeed, substantial evidence points to a key role of DA in the expression of impulsivity (Dalley and Roiser, 2012; Pattij and Vanderschuren, 2008). For example, binding of ligands for DA D2/D3 receptors in the

ventral striatum (predominantly $\left[{ }^{18} \mathrm{~F}\right]$-fallypride, $\left[{ }^{11} \mathrm{C}\right]$-raclopride) correlated negatively with questionnaire-based measures of impulsivity in healthy individuals (Reeves et al., 2012), pathological gamblers (Clark et al., 2012) and methamphetamine abusers (Lee et al., 2009). Similarly, rats with high levels of impulsive responding on the five choice serial reaction time task exhibited lower D2/D3 receptor availability in the ventral striatum (Dalley et al., 2007). D2/D3 receptor binding was also found to be lower in the dorsal striatum (Ghahremani et al., 2012), substantia nigra/ventral tegmental area (Buckholtz et al., 2010) and extra-striatal regions, including temporal cortex and thalamus (Bernow et al., 2011) of impulsive individuals. In one study, striatal D2/D3 receptor availability was found to correlate with neuronal activation, as measured by fMRI in the striatum and prefrontal cortex during performance of a Go/NoGo task (Ghahremani et al., 2012), suggesting a putative involvement of DA in response inhibition. This key finding is consistent with the reported correlation between striatal D2/D3 receptor binding and glucose metabolism in the OFC of stimulant abusers (Volkow et al., 2001). 
In addition to alterations in the regulation of D2/D3 receptors, impulsive individuals exhibit abnormalities in the release of DA in striatal regions. Thus, impulsivity in humans predicted enhanced amphetamine-induced DA release in the striatum, as indexed by the increased displacement of a D2/D3 receptor radioligand in this region (Buckholtz et al., 2010). Curiously, however, this positive relationship between impulsivity and striatal DA release did not extend to ADHD where DA release was decreased relative to healthy unaffected controls (Rosa-Neto et al., 2005).

\subsection{Neural correlates of novelty/sensation-seeking}

MRI investigations have consistently reported morphometric changes in cingulate cortex, inferior frontal gyrus, and hippocampus that correlate with questionnaire-based measures of novelty/sensation-seeking (Gardini et al., 2009; Martin et al., 2007; Van Schuerbeek et al., 2011). There is also evidence for enhanced connectivity, as measured by the number of fibers, from the hippocampus and amygdala to the striatum, in individuals with enhanced self-reported levels of novelty-seeking (Cohen et al., 2009). These structural differences are accompanied by alterations in baseline levels of neuronal activity, specifically enhanced $\left[{ }^{18} \mathrm{~F}\right]$-flurodeoxyglucose uptake and relative cerebral blood flow in the frontal and parietal cortical regions, including the ACC and insula (Hakamata et al., 2006; O'Gorman et al., 2006; Sugiura et al., 2000; Youn et al., 2002).

Unsurprisingly, novelty/sensation-seeking is associated with enhanced neuronal responses to novelty. In general, this trait appears to correlate with novelty-induced activation in the ventral tegmental area and ventral striatum (Krebs et al., 2009; Wittmann et al., 2008), as well as the hippocampus (Naghavi et al., 2009) and OFC (Lawson et al., 2012). In addition, neural responses to emotional or arousing pictures are enhanced in the prefrontal cortex (Bermpohl et al., 2008), insula and OFC (Joseph et al., 2009) of novelty/sensation- 
seekers. This pattern of activation most parsimoniously reflects an increased reactivity of these individuals to reward (e.g. (Stoops et al., 2007)). Thus, sensation-seekers showed increased activity following receipt of monetary reward in regions related to reward processing including the insula, prefrontal gyrus and ventral striatum (Cservenka et al., 2012; Kruschwitz et al., 2012). The same individuals showed reduced activity in these regions when confronted with a loss, or no-win situation, suggesting that sensation-seekers may be less sensitive to negative outcomes.

\subsection{Neurochemical correlates of novelty/sensation-seeking}

Like impulsivity, sensation/novelty-seeking is associated with dopaminergic dysfunction. Rats exhibiting high trait-like levels of novelty reactivity (i.e. HR rats) demonstrate enhanced basal and psychostimulant-induced DA release in the ventral striatum compared with their low novelty-reactive counterparts (Hooks et al., 1991; Piazza et al., 1989) and further show reduced D2/D3 receptor density in the dorsal and ventral striatum (Hooks et al., 1994). PET studies have broadly confirmed these findings. For example, novelty-reactive Gottingen minipigs showed enhanced amphetamine-induced DA release in the striatum (as measured by the change in binding of $\left[{ }^{11} \mathrm{C}\right]$-raclopride), similar to an analogous PET study in humans (Leyton et al., 2002). Moreover, sensation-seeking in humans was predicted by reduced D2/D3 receptor availability in the ventral tegmental area and substantia nigra (Zald et al., 2008) as well as the insular cortex (Suhara et al., 2001). Novelty reactivity was also found to correlate negatively with D2/D3 receptor availability in the caudate nucleus of cynomolgus monkeys (Czoty et al., 2010). Interestingly, novelty-reactive animals were found to be socially submissive. This finding fits well with studies demonstrating that reduced social rank is associated with reduced striatal D2/D3 receptor binding in healthy volunteers (Martinez et al., 2010). However, the relationship between striatal D2/D3 receptor availability and 
sensation-seeking in humans is apparently non-linear and best described by a quadratic, inverted U-shaped function (Gjedde et al., 2010). This complex relationship is thought to reflect the influence of elevated levels of endogenous DA (providing competition for radioligand binding) accompanied by reduced DA receptor availability in sensation-seeking individuals. Taken as a whole, these findings indicate that sensation-seeking is associated with hyper-dopaminergic function (in terms of DA release) in the striatum and midbrain, which may in turn contribute to the heightened reactivity to novelty and reward observed in these individuals (Krebs et al., 2009).

\subsection{Implications for the etiological basis of addiction}

Convergent findings from neuroimaging studies on the neurobiological basis of impulsivity and sensation-seeking have enabled a greater understanding of the causal role played by these traits in addiction. These studies have revealed a significant degree of overlap in markers of addiction and those relating to striatal DA function, the frontal cortical systems, and perturbations in reward processing in impulsivity and novelty/sensation-seeking.

Reduced striatal D2/D3 receptor binding is a highly conserved marker of impulsivity and sensation-seeking. D2/D3 receptor availability is also reduced in the striatum of cocaine (Volkow et al., 1993), methamphetamine (Volkow et al., 2001), heroin (Wang et al., 1997), cannabis (Sevy et al., 2008) and nicotine (Fehr et al., 2008) users, and further predicts enhanced relapse propensity in methamphetamine addicts (Wang et al., 2012). It is therefore possible that reduced striatal D2/D3 receptor binding in addicts represents, in part, a preexisting deficit and biological risk factor for the development of addiction. Evidence from studies in experimental animals provides some support for this notion. Subordinate cynomgous monkeys with a lowered baseline (i.e. pre-drug) availability of D2/D3 receptors in the striatum subsequently self-administered more cocaine than their dominant cage-mates 
(Morgan et al., 2002). Reduced striatal D2/D3 binding has also been associated with enhanced cocaine preference in rats and monkeys (Michaelides et al., 2012; Nader et al., 2006), and biased decision making in a rodent model of gambling (Cocker et al., 2012). Some or all of these consequences of reduced D2/D3 receptor availability may be amenable to computationally-derived models, for example, as a way of predicting drug self-administration (Piray et al., 2010).

However, notwithstanding the importance of individual variation in D2/D3 receptor availability as a trait risk marker for addiction, there is unequivocal evidence that chronic self-administration of stimulants is sufficient to decrease D2/D3 receptor availability in the striatum (e.g. (Ginovart et al., 1999; Nader et al., 2006)). Indeed, this view is supported by evidence that D2/D3 receptor availability correlates inversely with the duration of cocaine use in humans (Volkow et al., 1993). Thus, pre-existing reductions in DA receptor density, as found in impulsive individuals, for example, may be further compromised by chronic drug exposure. Recently, we tested this hypothesis by scanning highly impulsive rats on the fivechoice serial reaction time task on two occasions; initially to establish pre-drug $\left[{ }^{18} \mathrm{~F}\right]-$ fallypride binding potentials in the ventral and dorsal striatum and then again after a 2 -week period of long-access cocaine self-administration (Caprioli et al., 2013). We predicted that impulsivity would be exacerbated in highly impulsive rats if cocaine had the expected effects of further diminishing D2/D3 receptors in the ventral striatum. Our results indicated that prior cocaine exposure not only remediated impulsivity in trait impulsive rats it also increased D2/D3 receptor availability in both the ventral and dorsal striatum. Intriguingly, the direction of this effect (increase or decrease) depended on pre-drug D2/D3 receptor availability in the ventral and dorsal striatum. These results suggest that a key determinant of the behavioral outcome of stimulants in addiction-prone impulsive animals involves an interaction between baseline D2/3 receptor availability and the effects of extended access to cocaine and 
potentially other stimulant drugs as well. This interaction may be relevant to the observed ventral to dorsal shift in dopaminergic dysfunction that results from prolonged cocaine selfadministration (Porrino et al., 2004), postulated to underlie the development of maladaptive habit learning and ultimately compulsive drug seeking (Belin and Everitt, 2008; Everitt and Robbins, 2005, 2013).

The fact that impulsivity was normalized in highly impulsive rats by prior extended exposure to cocaine provides some validity to the idea that drug use in impulsive individuals reflects a form of 'self-medication'. Thus, medicating impulsive individuals may prevent the development of compulsive drug use and/or the occurrence of relapse in susceptible individuals, although clinical and pre-clinical studies confirming this therapeutic intervention are needed. Atomoxetine, a selective norepinephrine reuptake inhibitor, has been shown to decrease both impulsive responding (Fernando et al., 2012) and relapse to cocaine seeking (Economidou et al., 2009) in highly impulsive rats. Indeed, evidence from clinical trials indicates enhanced rates of abstinence following treatment with the related drug reboxetine in cocaine-dependent patients (Szerman et al., 2005), although studies using atomoxetine have failed to replicate these findings (Walsh et al., 2012).

Further shared findings between novelty/sensation-seeking and impulsivity include increased reward and stimulant-induced activity together with increased DA release in the ventral striatum (Buckholtz et al., 2010; Leyton et al., 2002). Enhanced DA release in this region has been suggested to reflect underlying reductions in midbrain D2/D3 receptors (Buckholtz et al., 2010). However, these findings do not resonate with observations made in addicts. Thus, while there is conflicting evidence regarding drug- and reward-induced striatal activity in addicts (reviewed in (Hommer et al., 2011)), a consensus has emerged that reward reactivity, and associated DA release, is reduced in the ventral striatum of addicts (e.g. (Narendran and Martinez, 2008)). This dichotomous set of findings may lie in the dissociable 
functions of D2 and D3 receptors to mediate DA responses at both pre- and post-synaptic membranes, as well as the differing anatomical distributions of these two receptor subtypes. Indeed it has been suggested that D3 receptors are increased in addicts. Thus, a recent study found that $\left[{ }^{11} \mathrm{C}\right](+)$ PHNO binding, a PET ligand exhibiting 25-48 fold greater selectivity for D3 receptors over D2 receptors (Gallezot et al., 2012), was increased in the substantia nigra of methamphetamine poly-drug users (Boileau et al., 2012). Acting presynaptically, an increase in these receptors may drive the decrease in DA release observed in addicts. However, while $\left[{ }^{11} \mathrm{C}\right](+)$ PHNO is a useful radioligand for the investigation of D3 receptors, it lacks absolute specificity and consequently the significance of these data must be interpreted with caution. Further, it is not possible to dissect the effect of chronic drug exposure on DA release in the ventral striatum and D2/D3 receptor availability in addicts. Thus, the observed reduction in ventral striatal reactivity observed in addicts may reflect the outcome of repeated drug use. Indeed chronic cocaine exposure has been found to reduce both basal and cocaine-evoked DA release in experimental animals (Kirkland Henry et al., 2009; Lee et al., 2011; Willuhn et al., 2012) and further has been found to correlate with the duration of drug use in cannabis addicts (Urban et al., 2012). Interestingly, cocaine-induced DA release in the ventral striatum has been shown to be critical for the later development of drug induced alterations in activity in the dorsal striatum thought to underlie the development of compulsive drug use in rats (Willuhn et al., 2012). Thus, enhanced ventral striatal activity associated with natural and drug rewards may preferentially recruit the circuitry required for the expression of compulsive drug use and in this way enhance risk for addiction in vulnerable individuals.

Beyond striatal dopaminergic mechanisms, individuals exhibiting enhanced levels of impulsivity and novelty/sensation-seeking also demonstrate significant, albeit contrasting 
alterations in functioning of the prefrontal cortex. Specifically, sensation-seeking has been associated with increased basal metabolic activity in this region and enhanced reactivity to emotionally-arousing stimuli (e.g. (Bermpohl et al., 2008; Youn et al., 2002)). By contrast, impulsivity is generally associated with hypofunctioning of the prefrontal cortex leading to deficiencies in cognitive control (Dalley et al., 2011). Thus, increased metabolic activity of prefrontal cortical regions observed in sensation-seekers contrasts distinctly with findings in impulsive individuals (e.g. (Oquendo et al., 2003)), as well as in drug addiction, where hypofrontality is generally reported (Goldstein and Volkow, 2011; Moreno-Lopez et al., 2012). Indeed, regional glucose metabolism is reduced in the dorsolateral prefrontal cortex of methamphetamine addicts (Kim et al., 2009) and was found to correlate inversely with the severity of heroin, alcohol, cannabis, cocaine and MDMA abuse (Moreno-Lopez et al., 2012). Nevertheless, there are reports suggesting that brain metabolism may be increased in metamphetamine addicts, although this may reflect inflammatory cascades within the brain related to neurotoxicity (e.g. (Berman et al., 2008)).

It is not clear whether alterations in brain metabolism reflects the neurotoxic effects of chronic drug use since grey matter volume is also generally decreased in drug addicts (Fein et al., 2002; Liu et al., 2009). In addition, OFC volume depends on the duration of drug use (Ersche et al., 2012a), whilst also being affected in impulsive individuals (Matsuo et al., 2009). Thus, OFC volume may be a risk marker for addiction that is subsequently exacerbated by chronic drug use. Previously, it was shown that hypometabolism in frontal cortex was linked to reduced striatal D2/D3 receptor availability in detoxified alcoholics (Volkow et al., 2006), as well as abusers of methamphetamine (Volkow et al., 2007) and cocaine (Volkow et al., 1993). This reduction in frontal metabolism may underlie deficits in inhibitory control observed in both impulsive individuals and addicts (Fu et al., 2008;

Kaufman et al., 2003). 
Remarkably, there is no evidence (at least in animal models) to suggest that sensationseeking is associated with deficits in response inhibition (Marusich et al., 2011), which may go some way to explaining why this behavioral trait is not associated with reductions in the activity of the prefrontal cortex. Indeed, the dissociation in deficits in response inhibitory control between sensation-seeking and impulsivity may relate to the apparent differential contribution of these two behavioral traits to addiction vulnerability (Belin et al., 2008; Ersche et al., 2010). It is also possible that enhanced activity in the prefrontal cortex observed in sensation-seekers (e.g. (Hakamata et al., 2006)) may contribute to the increased rates of drug use observed in these individuals (Ersche et al., 2012a) and in animal models of this trait, namely the HR rat (Belin et al., 2008).

Collectively, the findings reviewed above suggest the presence of several robust neurobehavioral makers associated with impulsivity and sensation/novelty-seeking that localize to cortico-striatal circuitry and which putatively underlie individual vulnerability for addiction (see Figure 1). These findings indicate a common involvement of diminished striatal D2/D3 receptor availability both in relation to predisposing traits and as a marker of prior drug abuse. However, this analysis also reveals important dissociations between frontal and striatal volume, as well as frontal metabolism, linked to impulsivity, sensation/noveltyseeking, and addiction. Such differences may reflect the increased propensity of sensation/novelty-seekers to initiate and maintain drug use but not develop diagnosticallyrelevant signs of addiction, unlike impulsive or impulsive/sensation-seeking individuals (Belin et al., 2011; Belin et al., 2008; Ersche et al., 2012a; Ersche et al., 2010). Clearly, in addition to these predisposing factors, repeated cycles of drug bingeing and withdrawal are likely to modify and hasten this transition, putatively through effects on the reactivity of the striatal systems to reward and OFC under-activity. How, and to what extent, each of these 
specific alterations in brain structure and function contribute to the development of compulsive drug seeking remains an important area for future research.

\subsection{Conclusions and future directions}

It is now generally accepted that the transition to addiction must entail pre-existing individual neurobiological risk factors, modified and exacerbated by both drug exposure and environmental variables. As reviewed here, the behavioural traits of impulsivity and sensation-seeking critically influence disease progression and show remarkable overlap with addiction with respect to DA dysfunction, altered brain metabolism and structure, as detected by neuroimaging studies in both humans and animal models. These shared mechanisms may represent underlying neurobiological risk factors for the development of drug addiction which may in turn be modulated by repeated bouts of drug bingeing and withdrawal (Nader et al., 2008) to hasten addiction. The effect of drug use to modify this neural background may account for some of the differences observed between the neuroimaging findings between addiction and impulsivity/sensation-seeking. The cascade of molecular mechanisms driving the shift from initial drug use to habitual and eventually compulsive drug seeking are unknown but are, without doubt, critically influenced by these predisposing behavioral endophenotypes and importantly therefore represent promising targets for developing new therapies in addiction.

Despite evidence for these shared mechanisms, particularly relating to DA dysfunction, there have been surprisingly few therapies developed for stimulant addiction based on pharmacological interventions of the brain DA systems (Christopher Pierce et al., 2012). In hindsight, this challenging failure in rational drug design is perhaps not surprising given current conceptualization of addiction as a progressive disorder characterized by pervasive 
and long-lasting disturbances in a complex myriad of neurotransmitter systems which includes glutamate, GABA, serotonin, noradrenaline and endogenous opioids, as well as DA (Kalivas and Volkow, 2011).

In turning to the future, it is clear that a more complete understanding of risk for addiction requires the non-invasive imaging of neurotransmitter systems other than the biogenic amines. In this regard promising PET ligands have been developed for the metabotropic glutamate receptors, mGluR1 and mGluR5 (Hostetler et al., 2011; Simeon et al., 2012), $\mathrm{GABA}_{\mathrm{A}}$ and $\mathrm{GABA}_{\mathrm{B}}$ receptors (Moran et al., 2012), and the noradrenergic transporter, the latter with promising results in cocaine addicts (Ding et al., 2010). As reviewed above, animal models have provided valuable insight into the neural and psychological mechanisms of compulsive drug self-administration, which implicate a broad network of brain structures and neurotransmitter systems (Everitt and Robbins, 2013), including the brain serotonin systems (Pelloux et al., 2012), for which excellent PET radioligands are available (e.g. $\left[{ }^{18} \mathrm{~F}\right]$ altanserin and $\left.\left[{ }^{11} \mathrm{C}\right] \mathrm{DASB}\right)$. Other promising leads include investigations of the endogenous opioid and cannabinoid systems, which powerfully modulate impulsivity (Wiskerke et al., 2011) and sensation/novelty-seeking (Van Laere et al., 2009).

The continued development of novel PET tracers and complementary structural and functional MRI approaches is expected to lead to further major discoveries in the field of addiction research. Central to this progress, and thereby the rationale development of new therapies, will be a greater understanding of brain mechanisms that confer individual vulnerability to the emergence of harmful drug use. 


\section{Acknowledgements}

This work was supported by the Medical Research Council (G0701500) and by a joint award from the Medical Research Council and Wellcome Trust in support of the Behavioural and Clinical Neuroscience Institute at Cambridge University. The authors also acknowledge funding from the MRC Imperial College-Cambridge University-Manchester (ICCAM) strategic addiction cluster. BJ is supported by a postdoctoral fellowship from the National Health and Medical Research Council of Australia (1016313).

\section{References}

Ambrosio, E., Goldberg, S. R., Elmer, G. I., 1995. Behavior genetic investigation of the relationship between spontaneous locomotor activity and the acquisition of morphine selfadministration behavior. Behav Pharmacol 6, 229-237.

Anker, J. J., Perry, J. L., Gliddon, L. A., Carroll, M. E., 2009. Impulsivity predicts the escalation of cocaine self-administration in rats. Pharmacol Biochem Behav 93, 343-348. Arnett, J., 1992. Reckless behaviour in adolescence: A developmental perspective. Developmental Review 12, 339-373.

Arnett, J., 1994. Sensation seeking: A new conceptualization and a new scale. Personality and Individual Differences 16, 289-296.

Aron, A. R., 2007. The neural basis of inhibition in cognitive control. Neuroscientist 13, 214 228.

Audrain-McGovern, J., Rodriguez, D., Epstein, L. H., Cuevas, J., Rodgers, K., Wileyto, E. P., 2009. Does delay discounting play an etiological role in smoking or is it a consequence of smoking? Drug Alcohol Depend 103, 99-106.

Ballard, K., Knutson, B., 2009. Dissociable neural representations of future reward magnitude and delay during temporal discounting. Neuroimage 45, 143-150.

Beckmann, J. S., Marusich, J. A., Gipson, C. D., Bardo, M. T., 2011. Novelty seeking, incentive salience and acquisition of cocaine self-administration in the rat. Behav Brain Res 216, 159-165.

Belin, D., Berson, N., Balado, E., Piazza, P. V., Deroche-Gamonet, V., 2011. High-noveltypreference rats are predisposed to compulsive cocaine self-administration.

Neuropsychopharmacology 36, 569-579. 
Belin, D., Deroche-Gamonet, V., 2012. Responses to novelty and vulnerability to cocaine addiction: contribution of a multi-symptomatic animal model. Cold Spring Harb Perspect Med 2.

Belin, D., Everitt, B. J., 2008. Cocaine seeking habits depend upon dopamine-dependent serial connectivity linking the ventral with the dorsal striatum. Neuron 57, 432-441.

Belin, D., Mar, A. C., Dalley, J. W., Robbins, T. W., Everitt, B. J., 2008. High impulsivity predicts the switch to compulsive cocaine-taking. Science 320, 1352-1355.

Berman, S. M., Voytek, B., Mandelkern, M. A., Hassid, B. D., Isaacson, A., Monterosso, J., Miotto, K., Ling, W., London, E. D., 2008. Changes in cerebral glucose metabolism during early abstinence from chronic methamphetamine abuse. Mol Psychiatry 13, 897-908.

Bermpohl, F., Pascual-Leone, A., Amedi, A., Merabet, L. B., Fregni, F., Wrase, J., Schlagenhauf, F., Bauer, M., Heinz, A., Schlaug, G., Northoff, G., 2008. Novelty seeking modulates medial prefrontal activity during the anticipation of emotional stimuli. Psychiatry Res 164, 81-85.

Bernow, N., Yakushev, I., Landvogt, C., Buchholz, H. G., Smolka, M. N., Bartenstein, P., Lieb, K., Grunder, G., Vernaleken, I., Schreckenberger, M., Fehr, C., 2011. Dopamine D2/D3 receptor availability and venturesomeness. Psychiatry Res 193, 80-84.

Bickel, W. K., Odum, A. L., Madden, G. J., 1999. Impulsivity and cigarette smoking: delay discounting in current, never, and ex-smokers. Psychopharmacology (Berl) 146, 447-454.

Bird, J., Schenk, S., 2012. Contribution of impulsivity and novelty-seeking to the acquisition and maintenance of MDMA self-administration. Addict Biol.

Blanchard, M. M., Mendelsohn, D., Stamp, J. A., 2009. The HR/LR model: Further evidence as an animal model of sensation seeking. Neurosci Biobehav Rev 33, 1145-1154.

Boileau, I., Payer, D., Houle, S., Behzadi, A., Rusjan, P. M., Tong, J., Wilkins, D., Selby, P., George, T. P., Zack, M., Furukawa, Y., McCluskey, T., Wilson, A. A., Kish, S. J., 2012. Higher binding of the dopamine D3 receptor-preferring ligand [11C]-(+)-propyl-hexahydronaphtho-oxazin in methamphetamine polydrug users: a positron emission tomography study. J Neurosci 32, 1353-1359.

Broos, N., Diergaarde, L., Schoffelmeer, A. N., Pattij, T., De Vries, T. J., 2012. Trait impulsive choice predicts resistance to extinction and propensity to relapse to cocaine seeking: a bidirectional investigation. Neuropsychopharmacology 37, 1377-1386. 
Brunelle, C., Assaad, J. M., Barrett, S. P., C, A. V., Conrod, P. J., Tremblay, R. E., Pihl, R. O., 2004. Heightened heart rate response to alcohol intoxication is associated with a rewardseeking personality profile. Alcohol Clin Exp Res 28, 394-401.

Buckholtz, J. W., Treadway, M. T., Cowan, R. L., Woodward, N. D., Li, R., Ansari, M. S., Baldwin, R. M., Schwartzman, A. N., Shelby, E. S., Smith, C. E., Kessler, R. M., Zald, D. H., 2010. Dopaminergic network differences in human impulsivity. Science 329, 532.

Caprioli, D., Hong, Y. T., Sawiak, S. J., Ferrari, V., Williamson, D. J., Jupp, B., Adrian Carpenter, T., Aigbirhio, F. I., Everitt, B. J., Robbins, T. W., Fryer, T. D., Dalley, J. W., 2013. Baseline-dependent effects of cocaine pre-exposure on impulsivity and $D(2 / 3)$ receptor availability in the rat striatum: Possible relevance to the attention-deficit hyperactivity syndrome. Neuropsychopharmacology.

Carmona, S., Proal, E., Hoekzema, E. A., Gispert, J. D., Picado, M., Moreno, I., Soliva, J. C., Bielsa, A., Rovira, M., Hilferty, J., Bulbena, A., Casas, M., Tobena, A., Vilarroya, O., 2009. Ventro-striatal reductions underpin symptoms of hyperactivity and impulsivity in attentiondeficit/hyperactivity disorder. Biol Psychiatry 66, 972-977.

Cho, S. S., Pellecchia, G., Aminian, K., Ray, N., Segura, B., Obeso, I., Strafella, A. P., 2012. Morphometric Correlation of Impulsivity in Medial Prefrontal Cortex. Brain Topogr. Christopher Pierce, R., O'Brien, C. P., Kenny, P. J., Vanderschuren, L. J., 2012. Rational development of addiction pharmacotherapies: successes, failures, and prospects. Cold Spring Harb Perspect Med 2, a012880.

Clark, L., Stokes, P. R., Wu, K., Michalczuk, R., Benecke, A., Watson, B. J., Egerton, A., Piccini, P., Nutt, D. J., Bowden-Jones, H., Lingford-Hughes, A. R., 2012. Striatal dopamine $\mathrm{D}(2) / \mathrm{D}(3)$ receptor binding in pathological gambling is correlated with mood-related impulsivity. Neuroimage 63, 40-46.

Cocker, P. J., Dinelle, K., Kornelson, R., Sossi, V., Winstanley, C. A., 2012. Irrational choice under uncertainty correlates with lower striatal $\mathrm{D}(2 / 3)$ receptor binding in rats. J Neurosci 32 , 15450-15457.

Cohen, M. X., Schoene-Bake, J. C., Elger, C. E., Weber, B., 2009. Connectivity-based segregation of the human striatum predicts personality characteristics. Nat Neurosci 12, 3234.

Cservenka, A., Herting, M. M., Seghete, K. L., Hudson, K. A., Nagel, B. J., 2012. High and low sensation seeking adolescents show distinct patterns of brain activity during reward processing. Neuroimage 66C, 184-193. 
Czoty, P. W., Gage, H. D., Nader, M. A., 2010. Differences in D2 dopamine receptor availability and reaction to novelty in socially housed male monkeys during abstinence from cocaine. Psychopharmacology (Berl) 208, 585-592.

Dalley, J. W., Everitt, B. J., Robbins, T. W., 2011. Impulsivity, compulsivity, and top-down cognitive control. Neuron 69, 680-694.

Dalley, J. W., Fryer, T. D., Brichard, L., Robinson, E. S., Theobald, D. E., Laane, K., Pena, Y., Murphy, E. R., Shah, Y., Probst, K., Abakumova, I., Aigbirhio, F. I., Richards, H. K., Hong, Y., Baron, J. C., Everitt, B. J., Robbins, T. W., 2007. Nucleus accumbens D2/3 receptors predict trait impulsivity and cocaine reinforcement. Science 315, 1267-1270. Dalley, J. W., Mar, A. C., Economidou, D., Robbins, T. W., 2008. Neurobehavioral mechanisms of impulsivity: fronto-striatal systems and functional neurochemistry. Pharmacol Biochem Behav 90, 250-260.

Dalley, J. W., Roiser, J. P., 2012. Dopamine, serotonin and impulsivity. Neuroscience 215, 42-58.

Daruma, J., Barnes, P., 1993. A neurodevelopmental view of impulsivity and its relationship to the superfactors of personality In: McCown, W., Johnson, J., Shure, M., (Eds), The impulsive client: theory, research and treatment. American Psychological Association Washington DC.

Davis, F. C., Knodt, A. R., Sporns, O., Lahey, B. B., Zald, D. H., Brigidi, B. D., Hariri, A. R., 2012. Impulsivity and the Modular Organization of Resting-State Neural Networks. Cereb Cortex.

de Wit, H., 2009. Impulsivity as a determinant and consequence of drug use: a review of underlying processes. Addict Biol 14, 22-31.

Diergaarde, L., Pattij, T., Poortvliet, I., Hogenboom, F., de Vries, W., Schoffelmeer, A. N., De Vries, T. J., 2008. Impulsive choice and impulsive action predict vulnerability to distinct stages of nicotine seeking in rats. Biol Psychiatry 63, 301-308.

Ding, Y. S., Singhal, T., Planeta-Wilson, B., Gallezot, J. D., Nabulsi, N., Labaree, D., Ropchan, J., Henry, S., Williams, W., Carson, R. E., Neumeister, A., Malison, R. T., 2010. PET imaging of the effects of age and cocaine on the norepinephrine transporter in the human brain using (S,S)-[(11)C]O-methylreboxetine and HRRT. Synapse 64, 30-38.

Dombrovski, A. Y., Siegle, G. J., Szanto, K., Clark, L., Reynolds, C. F., Aizenstein, H., 2012. The temptation of suicide: striatal gray matter, discounting of delayed rewards, and suicide attempts in late-life depression. Psychol Med 42, 1203-1215. 
Economidou, D., Pelloux, Y., Robbins, T. W., Dalley, J. W., Everitt, B. J., 2009. High impulsivity predicts relapse to cocaine-seeking after punishment-induced abstinence. Biol Psychiatry 65, 851-856.

Ernst, M., Paulus, M. P., 2005. Neurobiology of decision making: a selective review from a neurocognitive and clinical perspective. Biol Psychiatry 58, 597-604.

Ersche, K. D., Jones, P. S., Williams, G. B., Smith, D. G., Bullmore, E. T., Robbins, T. W., 2012a. Distinctive Personality Traits and Neural Correlates Associated with Stimulant Drug Use Versus Familial Risk of Stimulant Dependence. Biol Psychiatry.

Ersche, K. D., Turton, A. J., Chamberlain, S. R., Muller, U., Bullmore, E. T., Robbins, T. W., 2012b. Cognitive dysfunction and anxious-impulsive personality traits are endophenotypes for drug dependence. Am J Psychiatry 169, 926-936.

Ersche, K. D., Turton, A. J., Pradhan, S., Bullmore, E. T., Robbins, T. W., 2010. Drug addiction endophenotypes: impulsive versus sensation-seeking personality traits. Biol Psychiatry 68, 770-773.

Evenden, J. L., 1999. Varieties of impulsivity. Psychopharmacology (Berl) 146, 348-361. Everitt, B. J., Robbins, T. W., 2005. Neural systems of reinforcement for drug addiction: from actions to habits to compulsion. Nat Neurosci 8, 1481-1489.

Everitt, B. J., Robbins, T. W., 2013. From the ventral to the dorsal striatum: devolving views of their roles in drug addiction. Neurosci Biobehav Rev.

Farr, O. M., Hu, S., Zhang, S., Li, C. S., 2012. Decreased saliency processing as a neural measure of Barratt impulsivity in healthy adults. Neuroimage 63, 1070-1077.

Fehr, C., Yakushev, I., Hohmann, N., Buchholz, H. G., Landvogt, C., Deckers, H., Eberhardt, A., Klager, M., Smolka, M. N., Scheurich, A., Dielentheis, T., Schmidt, L. G., Rosch, F., Bartenstein, P., Grunder, G., Schreckenberger, M., 2008. Association of low striatal dopamine $\mathrm{d} 2$ receptor availability with nicotine dependence similar to that seen with other drugs of abuse. Am J Psychiatry 165, 507-514.

Fein, G., Di Sclafani, V., Meyerhoff, D. J., 2002. Prefrontal cortical volume reduction associated with frontal cortex function deficit in 6-week abstinent crack-cocaine dependent men. Drug Alcohol Depend 68, 87-93.

Fernando, A. B., Economidou, D., Theobald, D. E., Zou, M. F., Newman, A. H., Spoelder, M., Caprioli, D., Moreno, M., Hipomicronlito, L., Aspinall, A. T., Robbins, T. W., Dalley, J. W., 2012. Modulation of high impulsivity and attentional performance in rats by selective 
direct and indirect dopaminergic and noradrenergic receptor agonists. Psychopharmacology (Berl) 219, 341-352.

Fillmore, M. T., Rush, C. R., 2002. Impaired inhibitory control of behavior in chronic cocaine users. Drug Alcohol Depend 66, 265-273.

Flagel, S. B., Akil, H., Robinson, T. E., 2009. Individual differences in the attribution of incentive salience to reward-related cues: Implications for addiction. Neuropharmacology 56 Suppl 1, 139-148.

Flagel, S. B., Clark, J. J., Robinson, T. E., Mayo, L., Czuj, A., Willuhn, I., Akers, C. A., Clinton, S. M., Phillips, P. E., Akil, H., 2011. A selective role for dopamine in stimulusreward learning. Nature 469, 53-57.

Flagel, S. B., Robinson, T. E., Clark, J. J., Clinton, S. M., Watson, S. J., Seeman, P., Phillips, P. E., Akil, H., 2010. An animal model of genetic vulnerability to behavioral disinhibition and responsiveness to reward-related cues: implications for addiction.

Neuropsychopharmacology 35, 388-400.

Fortune, E. E., Goodie, A. S., 2010. The relationship between pathological gambling and sensation seeking: the role of subscale scores. J Gambl Stud 26, 331-346.

Frodl, T., 2010. Comorbidity of ADHD and Substance Use Disorder (SUD): a neuroimaging perspective. J Atten Disord 14, 109-120.

Fu, L. P., Bi, G. H., Zou, Z. T., Wang, Y., Ye, E. M., Ma, L., Ming, F., Yang, Z., 2008.

Impaired response inhibition function in abstinent heroin dependents: an fMRI study. Neurosci Lett 438, 322-326.

Gallezot, J. D., Beaver, J. D., Gunn, R. N., Nabulsi, N., Weinzimmer, D., Singhal, T., Slifstein, M., Fowles, K., Ding, Y. S., Huang, Y., Laruelle, M., Carson, R. E., Rabiner, E. A., 2012. Affinity and selectivity of [(1)(1)C]-(+)-PHNO for the D3 and D2 receptors in the rhesus monkey brain in vivo. Synapse 66, 489-500.

Garavan, H., Kaufman, J. N., Hester, R., 2008. Acute effects of cocaine on the neurobiology of cognitive control. Philos Trans R Soc Lond B Biol Sci 363, 3267-3276.

Garcia-Lecumberri, C., Torres, I., Martin, S., Crespo, J. A., Miguens, M., Nicanor, C., Higuera-Matas, A., Ambrosio, E., 2011. Strain differences in the dose-response relationship for morphine self-administration and impulsive choice between Lewis and Fischer 344 rats. J Psychopharmacol 25, 783-791.

Gardini, S., Cloninger, C. R., Venneri, A., 2009. Individual differences in personality traits reflect structural variance in specific brain regions. Brain Res Bull 79, 265-270. 
Gerra, G., Angioni, L., Zaimovic, A., Moi, G., Bussandri, M., Bertacca, S., Santoro, G., Gardini, S., Caccavari, R., Nicoli, M. A., 2004. Substance use among high-school students: relationships with temperament, personality traits, and parental care perception. Subst Use Misuse 39, 345-367.

Ghahremani, D. G., Lee, B., Robertson, C. L., Tabibnia, G., Morgan, A. T., De Shetler, N., Brown, A. K., Monterosso, J. R., Aron, A. R., Mandelkern, M. A., Poldrack, R. A., London, E. D., 2012. Striatal dopamine $\mathrm{D}(2) / \mathrm{D}(3)$ receptors mediate response inhibition and related activity in frontostriatal neural circuitry in humans. J Neurosci 32, 7316-7324.

Ginovart, N., Farde, L., Halldin, C., Swahn, C. G., 1999. Changes in striatal D2-receptor density following chronic treatment with amphetamine as assessed with PET in nonhuman primates. Synapse 31, 154-162.

Giorgi, O., Piras, G., Corda, M. G., 2007. The psychogenetically selected Roman high- and low-avoidance rat lines: a model to study the individual vulnerability to drug addiction.

Neurosci Biobehav Rev 31, 148-163.

Gjedde, A., Kumakura, Y., Cumming, P., Linnet, J., Moller, A., 2010. Inverted-U-shaped correlation between dopamine receptor availability in striatum and sensation seeking. Proc Natl Acad Sci U S A 107, 3870-3875.

Goldstein, R. Z., Volkow, N. D., 2011. Dysfunction of the prefrontal cortex in addiction: neuroimaging findings and clinical implications. Nat Rev Neurosci 12, 652-669.

Hakamata, Y., Iwase, M., Iwata, H., Kobayashi, T., Tamaki, T., Nishio, M., Kawahara, K., Matsuda, H., Ozaki, N., Honjo, S., Inada, T., 2006. Regional brain cerebral glucose metabolism and temperament: a positron emission tomography study. Neurosci Lett 396, 3337.

Hariri, A. R., 2009. The neurobiology of individual differences in complex behavioral traits. Annu Rev Neurosci 32, 225-247.

Hariri, A. R., Brown, S. M., Williamson, D. E., Flory, J. D., de Wit, H., Manuck, S. B., 2006. Preference for immediate over delayed rewards is associated with magnitude of ventral striatal activity. J Neurosci 26, 13213-13217.

Hester, R., Garavan, H., 2004. Executive dysfunction in cocaine addiction: evidence for discordant frontal, cingulate, and cerebellar activity. J Neurosci 24, 11017-11022.

Hinvest, N. S., Elliott, R., McKie, S., Anderson, I. M., 2011. Neural correlates of choice behavior related to impulsivity and venturesomeness. Neuropsychologia 49, 2311-2320. 
Hittner, J. B., Swickert, R., 2006. Sensation seeking and alcohol use: a meta-analytic review. Addict Behav 31, 1383-1401.

Hommer, D. W., Bjork, J. M., Gilman, J. M., 2011. Imaging brain response to reward in addictive disorders. Ann N Y Acad Sci 1216, 50-61.

Hooks, M. S., Jones, G. H., Smith, A. D., Neill, D. B., Justice, J. B., Jr., 1991. Response to novelty predicts the locomotor and nucleus accumbens dopamine response to cocaine. Synapse 9, 121-128.

Hooks, M. S., Juncos, J. L., Justice, J. B., Jr., Meiergerd, S. M., Povlock, S. L., Schenk, J. O., Kalivas, P. W., 1994. Individual locomotor response to novelty predicts selective alterations in D1 and D2 receptors and mRNAs. J Neurosci 14, 6144-6152.

Hostetler, E. D., Sanabria-Bohorquez, S., Fan, H., Zeng, Z., Gammage, L., Miller, P., O'Malley, S., Connolly, B., Mulhearn, J., Harrison, S. T., Wolkenberg, S. E., Barrow, J. C., Williams, D. L., Jr., Hargreaves, R. J., Sur, C., Cook, J. J., 2011.

[18F]Fluoroazabenzoxazoles as potential amyloid plaque PET tracers: synthesis and in vivo evaluation in rhesus monkey. Nucl Med Biol 38, 1193-1203.

Hutchison, K. E., Wood, M. D., Swift, R., 1999. Personality factors moderate subjective and psychophysiological responses to d-amphetamine in humans. Exp Clin Psychopharmacol 7 , 493-501.

Joseph, J. E., Liu, X., Jiang, Y., Lynam, D., Kelly, T. H., 2009. Neural correlates of emotional reactivity in sensation seeking. Psychol Sci 20, 215-223.

Jupp, B., Caprioli, D., Dalley, J. W., 2013. Highly impulsive rats: modelling an endophenotype to determine the neurobiological, genetic and environmental mechanisms of addiction. Dis Model Mech 6, 302-311.

Kalivas, P. W., Volkow, N. D., 2005. The neural basis of addiction: a pathology of motivation and choice. Am J Psychiatry 162, 1403-1413.

Kalivas, P. W., Volkow, N. D., 2011. New medications for drug addiction hiding in glutamatergic neuroplasticity. Mol Psychiatry 16, 974-986.

Kaufman, J. N., Ross, T. J., Stein, E. A., Garavan, H., 2003. Cingulate hypoactivity in cocaine users during a GO-NOGO task as revealed by event-related functional magnetic resonance imaging. J Neurosci 23, 7839-7843.

Kim, Y. T., Lee, S. W., Kwon, D. H., Seo, J. H., Ahn, B. C., Lee, J., 2009. Dose-dependent frontal hypometabolism on FDG-PET in methamphetamine abusers. J Psychiatr Res 43, 1166-1170. 
Kirby, K. N., Petry, N. M., 2004. Heroin and cocaine abusers have higher discount rates for delayed rewards than alcoholics or non-drug-using controls. Addiction 99, 461-471.

Kirkland Henry, P., Davis, M., Howell, L. L., 2009. Effects of cocaine self-administration history under limited and extended access conditions on in vivo striatal dopamine neurochemistry and acoustic startle in rhesus monkeys. Psychopharmacology (Berl) 205, 237-247.

Konrad, A., Dielentheis, T. F., El Masri, D., Bayerl, M., Fehr, C., Gesierich, T., Vucurevic, G., Stoeter, P., Winterer, G., 2010. Disturbed structural connectivity is related to inattention and impulsivity in adult attention deficit hyperactivity disorder. Eur J Neurosci 31, 912-919. Krebs, R. M., Schott, B. H., Duzel, E., 2009. Personality traits are differentially associated with patterns of reward and novelty processing in the human substantia nigra/ventral tegmental area. Biol Psychiatry 65, 103-110.

Kreek, M. J., Levran, O., Reed, B., Schlussman, S. D., Zhou, Y., Butelman, E. R., 2012. Opiate addiction and cocaine addiction: underlying molecular neurobiology and genetics. $\mathrm{J}$ Clin Invest 122, 3387-3393.

Kreek, M. J., Nielsen, D. A., Butelman, E. R., LaForge, K. S., 2005. Genetic influences on impulsivity, risk taking, stress responsivity and vulnerability to drug abuse and addiction. Nat Neurosci 8, 1450-1457.

Kruschwitz, J. D., Simmons, A. N., Flagan, T., Paulus, M. P., 2012. Nothing to lose: processing blindness to potential losses drives thrill and adventure seekers. Neuroimage 59, 2850-2859.

Kumari, V., Barkataki, I., Goswami, S., Flora, S., Das, M., Taylor, P., 2009. Dysfunctional, but not functional, impulsivity is associated with a history of seriously violent behaviour and reduced orbitofrontal and hippocampal volumes in schizophrenia. Psychiatry Res 173, 39-44. Lawson, A. L., Liu, X., Joseph, J., Vagnini, V. L., Kelly, T. H., Jiang, Y., 2012. Sensation seeking predicts brain responses in the old-new task: converging multimodal neuroimaging evidence. Int J Psychophysiol 84, 260-269.

Lee, B., London, E. D., Poldrack, R. A., Farahi, J., Nacca, A., Monterosso, J. R., Mumford, J. A., Bokarius, A. V., Dahlbom, M., Mukherjee, J., Bilder, R. M., Brody, A. L., Mandelkern, M. A., 2009. Striatal dopamine $\mathrm{d} 2 / \mathrm{d} 3$ receptor availability is reduced in methamphetamine dependence and is linked to impulsivity. J Neurosci 29, 14734-14740. 
Lee, J., Parish, C. L., Tomas, D., Horne, M. K., 2011. Chronic cocaine administration reduces striatal dopamine terminal density and striatal dopamine release which leads to drug-seeking behaviour. Neuroscience 174, 143-150.

Leyton, M., Boileau, I., Benkelfat, C., Diksic, M., Baker, G., Dagher, A., 2002.

Amphetamine-induced increases in extracellular dopamine, drug wanting, and novelty seeking: a PET/[11C]raclopride study in healthy men. Neuropsychopharmacology 27, 10271035 .

Liu, H., Hao, Y., Kaneko, Y., Ouyang, X., Zhang, Y., Xu, L., Xue, Z., Liu, Z., 2009. Frontal and cingulate gray matter volume reduction in heroin dependence: optimized voxel-based morphometry. Psychiatry Clin Neurosci 63, 563-568.

Liu, J., Zubieta, J. K., Heitzeg, M., 2012. Sex differences in anterior cingulate cortex activation during impulse inhibition and behavioral correlates. Psychiatry Res 201, 54-62. Madden, G. J., Petry, N. M., Badger, G. J., Bickel, W. K., 1997. Impulsive and self-control choices in opioid-dependent patients and non-drug-using control participants: drug and monetary rewards. Exp Clin Psychopharmacol 5, 256-262.

Maremmani, I., Pacini, M., Popovic, D., Romano, A., Maremmani, A. G., Perugi, G., Deltito, J., Akiskal, K., Akiskal, H., 2009. Affective temperaments in heroin addiction. J Affect Disord 117, 186-192.

Marinelli, M., White, F. J., 2000. Enhanced vulnerability to cocaine self-administration is associated with elevated impulse activity of midbrain dopamine neurons. J Neurosci 20, 8876-8885.

Martin, S. B., Covell, D. J., Joseph, J. E., Chebrolu, H., Smith, C. D., Kelly, T. H., Jiang, Y., Gold, B. T., 2007. Human experience seeking correlates with hippocampus volume: convergent evidence from manual tracing and voxel-based morphometry. Neuropsychologia 45, 2874-2881.

Martinez, D., Orlowska, D., Narendran, R., Slifstein, M., Liu, F., Kumar, D., Broft, A., Van Heertum, R., Kleber, H. D., 2010. Dopamine type 2/3 receptor availability in the striatum and social status in human volunteers. Biol Psychiatry 67, 275-278.

Marusich, J. A., Bardo, M. T., 2009. Differences in impulsivity on a delay-discounting task predict self-administration of a low unit dose of methylphenidate in rats. Behav Pharmacol $20,447-454$.

Marusich, J. A., Darna, M., Charnigo, R. J., Dwoskin, L. P., Bardo, M. T., 2011. A multivariate assessment of individual differences in sensation seeking and impulsivity as 
predictors of amphetamine self-administration and prefrontal dopamine function in rats. Exp Clin Psychopharmacol 19, 275-284.

Matsuo, K., Nicoletti, M., Nemoto, K., Hatch, J. P., Peluso, M. A., Nery, F. G., Soares, J. C., 2009. A voxel-based morphometry study of frontal gray matter correlates of impulsivity. Hum Brain Mapp 30, 1188-1195.

McNamara, R., Dalley, J. W., Robbins, T. W., Everitt, B. J., Belin, D., 2010. Trait-like impulsivity does not predict escalation of heroin self-administration in the rat. Psychopharmacology (Berl) 212, 453-464.

Mendez, I. A., Simon, N. W., Hart, N., Mitchell, M. R., Nation, J. R., Wellman, P. J., Setlow, B., 2010. Self-administered cocaine causes long-lasting increases in impulsive choice in a delay discounting task. Behav Neurosci 124, 470-477.

Meyer-Lindenberg, A., Weinberger, D. R., 2006. Intermediate phenotypes and genetic mechanisms of psychiatric disorders. Nat Rev Neurosci 7, 818-827.

Michaelides, M., Thanos, P. K., Kim, R., Cho, J., Ananth, M., Wang, G. J., Volkow, N. D., 2012. PET imaging predicts future body weight and cocaine preference. Neuroimage 59, $1508-1513$.

Moeller, F. G., Dougherty, D. M., Barratt, E. S., Oderinde, V., Mathias, C. W., Harper, R. A., Swann, A. C., 2002. Increased impulsivity in cocaine dependent subjects independent of antisocial personality disorder and aggression. Drug Alcohol Depend 68, 105-111.

Moeller, F. G., Dougherty, D. M., Barratt, E. S., Schmitz, J. M., Swann, A. C., Grabowski, J., 2001. The impact of impulsivity on cocaine use and retention in treatment. J Subst Abuse Treat 21, 193-198.

Molander, A. C., Mar, A., Norbury, A., Steventon, S., Moreno, M., Caprioli, D., Theobald, D. E., Belin, D., Everitt, B. J., Robbins, T. W., Dalley, J. W., 2011. High impulsivity predicting vulnerability to cocaine addiction in rats: some relationship with novelty preference but not novelty reactivity, anxiety or stress. Psychopharmacology (Berl) 215, 721 731.

Monterosso, J. R., Ainslie, G., Xu, J., Cordova, X., Domier, C. P., London, E. D., 2007. Frontoparietal cortical activity of methamphetamine-dependent and comparison subjects performing a delay discounting task. Hum Brain Mapp 28, 383-393.

Monterosso, J. R., Aron, A. R., Cordova, X., Xu, J., London, E. D., 2005. Deficits in response inhibition associated with chronic methamphetamine abuse. Drug Alcohol Depend $79,273-277$. 
Moran, M. D., Wilson, A. A., Elmore, C. S., Parkes, J., Ng, A., Sadovski, O., Graff, A., Daskalakis, Z. J., Houle, S., Chapdelaine, M. J., Vasdev, N., 2012. Development of new carbon-11 labelled radiotracers for imaging GABAA- and GABAB-benzodiazepine receptors. Bioorg Med Chem 20, 4482-4488.

Moreno-Lopez, L., Stamatakis, E. A., Fernandez-Serrano, M. J., Gomez-Rio, M., RodriguezFernandez, A., Perez-Garcia, M., Verdejo-Garcia, A., 2012. Neural correlates of the severity of cocaine, heroin, alcohol, MDMA and cannabis use in polysubstance abusers: a restingPET brain metabolism study. PLoS One 7, e39830.

Morgan, D., Grant, K. A., Gage, H. D., Mach, R. H., Kaplan, J. R., Prioleau, O., Nader, S. H., Buchheimer, N., Ehrenkaufer, R. L., Nader, M. A., 2002. Social dominance in monkeys: dopamine D2 receptors and cocaine self-administration. Nat Neurosci 5, 169-174.

Muller, S. E., Weijers, H. G., Boning, J., Wiesbeck, G. A., 2008. Personality traits predict treatment outcome in alcohol-dependent patients. Neuropsychobiology 57, 159-164.

Nadal, R., Armario, A., Janak, P. H., 2002. Positive relationship between activity in a novel environment and operant ethanol self-administration in rats. Psychopharmacology (Berl) 162, 333-338.

Nader, M. A., Czoty, P. W., Gould, R. W., Riddick, N. V., 2008. Review. Positron emission tomography imaging studies of dopamine receptors in primate models of addiction. Philos Trans R Soc Lond B Biol Sci 363, 3223-3232.

Nader, M. A., Czoty, P. W., Nader, S. H., Morgan, D., 2012. Nonhuman primate models of social behavior and cocaine abuse. Psychopharmacology (Berl) 224, 57-67.

Nader, M. A., Morgan, D., Gage, H. D., Nader, S. H., Calhoun, T. L., Buchheimer, N., Ehrenkaufer, R., Mach, R. H., 2006. PET imaging of dopamine D2 receptors during chronic cocaine self-administration in monkeys. Nat Neurosci 9, 1050-1056.

Naghavi, H. R., Lind, J., Nilsson, L. G., Adolfsson, R., Nyberg, L., 2009. Personality traits predict response to novel and familiar stimuli in the hippocampal region. Psychiatry Res 173, 94-99.

Narendran, R., Martinez, D., 2008. Cocaine abuse and sensitization of striatal dopamine transmission: a critical review of the preclinical and clinical imaging literature. Synapse 62, 851-869.

Nees, F., Tzschoppe, J., Patrick, C. J., Vollstadt-Klein, S., Steiner, S., Poustka, L., Banaschewski, T., Barker, G. J., Buchel, C., Conrod, P. J., Garavan, H., Heinz, A., Gallinat, J., Lathrop, M., Mann, K., Artiges, E., Paus, T., Poline, J. B., Robbins, T. W., Rietschel, M., 
Smolka, M. N., Spanagel, R., Struve, M., Loth, E., Schumann, G., Flor, H., 2012.

Determinants of early alcohol use in healthy adolescents: the differential contribution of neuroimaging and psychological factors. Neuropsychopharmacology 37, 986-995.

Nigg, J. T., Wong, M. M., Martel, M. M., Jester, J. M., Puttler, L. I., Glass, J. M., Adams, K. M., Fitzgerald, H. E., Zucker, R. A., 2006. Poor response inhibition as a predictor of problem drinking and illicit drug use in adolescents at risk for alcoholism and other substance use disorders. J Am Acad Child Adolesc Psychiatry 45, 468-475.

Noel, X., Brevers, D., Bechara, A., Hanak, C., Kornreich, C., Verbanck, P., Le Bon, O., 2011. Neurocognitive determinants of novelty and sensation-seeking in individuals with alcoholism. Alcohol Alcohol 46, 407-415.

Noel, X., Van der Linden, M., d'Acremont, M., Bechara, A., Dan, B., Hanak, C., Verbanck, P., 2007. Alcohol cues increase cognitive impulsivity in individuals with alcoholism.

Psychopharmacology (Berl) 192, 291-298.

O'Callaghan, C., Naismith, S. L., Hodges, J. R., Lewis, S. J., Hornberger, M., 2012. Frontostriatal atrophy correlates of inhibitory dysfunction in Parkinson's disease versus behavioural variant frontotemporal dementia. Cortex.

O'Gorman, R. L., Kumari, V., Williams, S. C., Zelaya, F. O., Connor, S. E., Alsop, D. C., Gray, J. A., 2006. Personality factors correlate with regional cerebral perfusion. Neuroimage 31, 489-495.

Oberlin, B. G., Grahame, N. J., 2009. High-alcohol preferring mice are more impulsive than low-alcohol preferring mice as measured in the delay discounting task. Alcohol Clin Exp Res 33, 1294-1303.

Onn, S. P., West, A. R., Grace, A. A., 2000. Dopamine-mediated regulation of striatal neuronal and network interactions. Trends Neurosci 23, S48-56.

Oquendo, M. A., Placidi, G. P., Malone, K. M., Campbell, C., Keilp, J., Brodsky, B., Kegeles, L. S., Cooper, T. B., Parsey, R. V., van Heertum, R. L., Mann, J. J., 2003. Positron emission tomography of regional brain metabolic responses to a serotonergic challenge and lethality of suicide attempts in major depression. Arch Gen Psychiatry 60, 14-22.

Paine, T. A., Dringenberg, H. C., Olmstead, M. C., 2003. Effects of chronic cocaine on impulsivity: relation to cortical serotonin mechanisms. Behav Brain Res 147, 135-147. Parvaz, M. A., Alia-Klein, N., Woicik, P. A., Volkow, N. D., Goldstein, R. Z., 2011. Neuroimaging for drug addiction and related behaviors. Rev Neurosci 22, 609-624. 
Pascual, J. C., Soler, J., Baiget, M., Cortes, A., Menoyo, A., Barrachina, J., Ropero, M., Goma, M., Alvarez, E., Perez, V., 2007. Association between the serotonin transporter gene and personality traits in borderline personality disorder patients evaluated with ZuckermanZuhlman Personality Questionnaire (ZKPQ). Actas Esp Psiquiatr 35, 382-386.

Patkar, A. A., Murray, H. W., Mannelli, P., Gottheil, E., Weinstein, S. P., Vergare, M. J., 2004. Pre-treatment measures of impulsivity, aggression and sensation seeking are associated with treatment outcome for African-American cocaine-dependent patients. J Addict Dis 23, 109-122.

Pattij, T., Vanderschuren, L. J., 2008. The neuropharmacology of impulsive behaviour. Trends Pharmacol Sci 29, 192-199.

Pelloux, Y., Dilleen, R., Economidou, D., Theobald, D., Everitt, B. J., 2012. Reduced forebrain serotonin transmission is causally involved in the development of compulsive cocaine seeking in rats. Neuropsychopharmacology 37, 2505-2514.

Peper, J. S., Mandl, R. C., Braams, B. R., de Water, E., Heijboer, A. C., Koolschijn, P. C., Crone, E. A., 2012. Delay Discounting and Frontostriatal Fiber Tracts: A Combined DTI and MTR Study on Impulsive Choices in Healthy Young Adults. Cereb Cortex.

Petry, N. M., 2001. Delay discounting of money and alcohol in actively using alcoholics, currently abstinent alcoholics, and controls. Psychopharmacology (Berl) 154, 243-250.

Piazza, P. V., Deminiere, J. M., Le Moal, M., Simon, H., 1989. Factors that predict individual vulnerability to amphetamine self-administration. Science 245, 1511-1513.

Piazza, P. V., Deminiere, J. M., Maccari, S., Mormede, P., Le Moal, M., Simon, H., 1990. Individual reactivity to novelty predicts probability of amphetamine self-administration. Behav Pharmacol 1, 339-345.

Piazza, P. V., Deroche-Gamonent, V., Rouge-Pont, F., Le Moal, M., 2000. Vertical shifts in self-administration dose-response functions predict a drug-vulnerable phenotype predisposed to addiction. J Neurosci 20, 4226-4232.

Piazza, P. V., Deroche, V., Rouge-Pont, F., Le Moal, M., 1998. Behavioral and biological factors associated with individual vulnerability to psychostimulant abuse. NIDA Res Monogr $169,105-133$.

Piray, P., Keramati, M. M., Dezfouli, A., Lucas, C., Mokri, A., 2010. Individual differences in nucleus accumbens dopamine receptors predict development of addiction-like behavior: a computational approach. Neural Comput 22, 2334-2368. 
Porrino, L. J., Lyons, D., Smith, H. R., Daunais, J. B., Nader, M. A., 2004. Cocaine selfadministration produces a progressive involvement of limbic, association, and sensorimotor striatal domains. J Neurosci 24, 3554-3562.

Poulos, C. X., Le, A. D., Parker, J. L., 1995. Impulsivity predicts individual susceptibility to high levels of alcohol self-administration. Behav Pharmacol 6, 810-814.

Radwanska, K., Kaczmarek, L., 2012. Characterization of an alcohol addiction-prone phenotype in mice. Addict Biol 17, 601-612.

Reeves, S. J., Polling, C., Stokes, P. R., Lappin, J. M., Shotbolt, P. P., Mehta, M. A., Howes, O. D., Egerton, A., 2012. Limbic striatal dopamine D2/3 receptor availability is associated with non-planning impulsivity in healthy adults after exclusion of potential dissimulators. Psychiatry Res 202, 60-64.

Ripke, S., Hubner, T., Mennigen, E., Muller, K. U., Rodehacke, S., Schmidt, D., Jacob, M. J., Smolka, M. N., 2012. Reward processing and intertemporal decision making in adults and adolescents: the role of impulsivity and decision consistency. Brain Res 1478, 36-47.

Robbins, T. W., 2002. The 5-choice serial reaction time task: behavioural pharmacology and functional neurochemistry. Psychopharmacology (Berl) 163, 362-380.

Robbins, T. W., Gillan, C. M., Smith, D. G., de Wit, S., Ersche, K. D., 2012. Neurocognitive endophenotypes of impulsivity and compulsivity: towards dimensional psychiatry. Trends Cogn Sci 16, 81-91.

Roesch, M. R., Takahashi, Y., Gugsa, N., Bissonette, G. B., Schoenbaum, G., 2007. Previous cocaine exposure makes rats hypersensitive to both delay and reward magnitude. J Neurosci $27,245-250$.

Rogers, R. D., Robbins, T. W., 2001. Investigating the neurocognitive deficits associated with chronic drug misuse. Curr Opin Neurobiol 11, 250-257.

Rosa-Neto, P., Lou, H. C., Cumming, P., Pryds, O., Karrebaek, H., Lunding, J., Gjedde, A., 2005. Methylphenidate-evoked changes in striatal dopamine correlate with inattention and impulsivity in adolescents with attention deficit hyperactivity disorder. Neuroimage 25, 868876.

Sala, M., Caverzasi, E., Lazzaretti, M., Morandotti, N., De Vidovich, G., Marraffini, E., Gambini, F., Isola, M., De Bona, M., Rambaldelli, G., d'Allio, G., Barale, F., Zappoli, F., Brambilla, P., 2011. Dorsolateral prefrontal cortex and hippocampus sustain impulsivity and aggressiveness in borderline personality disorder. J Affect Disord 131, 417-421. 
Sargent, J. D., Tanski, S., Stoolmiller, M., Hanewinkel, R., 2010. Using sensation seeking to target adolescents for substance use interventions. Addiction 105, 506-514.

Saunders, B. T., Robinson, T. E., 2010. A cocaine cue acts as an incentive stimulus in some but not others: implications for addiction. Biol Psychiatry 67, 730-736.

Schilling, C., Kuhn, S., Romanowski, A., Schubert, F., Kathmann, N., Gallinat, J., 2012.

Cortical thickness correlates with impulsiveness in healthy adults. Neuroimage 59, 824-830.

Schippers, M. C., Binnekade, R., Schoffelmeer, A. N., Pattij, T., De Vries, T. J., 2012.

Unidirectional relationship between heroin self-administration and impulsive decisionmaking in rats. Psychopharmacology (Berl) 219, 443-452.

Schmaal, L., Goudriaan, A. E., van der Meer, J., van den Brink, W., Veltman, D. J., 2012. The association between cingulate cortex glutamate concentration and delay discounting is mediated by resting state functional connectivity. Brain Behav 2, 553-562.

Semple, S. J., Zians, J., Grant, I., Patterson, T. L., 2005. Impulsivity and methamphetamine use. J Subst Abuse Treat 29, 85-93.

Sevy, S., Smith, G. S., Ma, Y., Dhawan, V., Chaly, T., Kingsley, P. B., Kumra, S., Abdelmessih, S., Eidelberg, D., 2008. Cerebral glucose metabolism and D2/D3 receptor availability in young adults with cannabis dependence measured with positron emission tomography. Psychopharmacology (Berl) 197, 549-556.

Shao, R., Read, J., Behrens, T. E., Rogers, R. D., 2013. Shifts in reinforcement signalling while playing slot-machines as a function of prior experience and impulsivity. Transl Psychiatry 3, e213.

Simeon, F. G., Liow, J. S., Zhang, Y., Hong, J., Gladding, R. L., Zoghbi, S. S., Innis, R. B., Pike, V. W., 2012. Synthesis and characterization in monkey of [11C]SP203 as a radioligand for imaging brain metabotropic glutamate 5 receptors. Eur J Nucl Med Mol Imaging 39, 1949-1958.

Solanto, M. V., 2002. Dopamine dysfunction in AD/HD: integrating clinical and basic neuroscience research. Behav Brain Res 130, 65-71.

Soloff, P. H., Meltzer, C. C., Becker, C., Greer, P. J., Kelly, T. M., Constantine, D., 2003. Impulsivity and prefrontal hypometabolism in borderline personality disorder. Psychiatry Res 123, 153-163.

Sonuga-Barke, E. J., 2002. Psychological heterogeneity in AD/HD--a dual pathway model of behaviour and cognition. Behav Brain Res 130, 29-36. 
Spear, L. P., 2000. The adolescent brain and age-related behavioral manifestations. Neurosci Biobehav Rev 24, 417-463.

Spillane, N. S., Muller, C. J., Noonan, C., Goins, R. T., Mitchell, C. M., Manson, S., 2012. Sensation-seeking predicts initiation of daily smoking behavior among American Indian high school students. Addict Behav 37, 1303-1306.

Sripada, C. S., Gonzalez, R., Phan, K. L., Liberzon, I., 2011. The neural correlates of intertemporal decision-making: contributions of subjective value, stimulus type, and trait impulsivity. Hum Brain Mapp 32, 1637-1648.

Stephenson, M. T., Helme, D. W., 2006. Authoritative parenting and sensation seeking as predictors of adolescent cigarette and marijuana use. J Drug Educ 36, 247-270.

Stoops, W. W., Lile, J. A., Robbins, C. G., Martin, C. A., Rush, C. R., Kelly, T. H., 2007. The reinforcing, subject-rated, performance, and cardiovascular effects of d-amphetamine: influence of sensation-seeking status. Addict Behav 32, 1177-1188.

Strohle, A., Stoy, M., Wrase, J., Schwarzer, S., Schlagenhauf, F., Huss, M., Hein, J., Nedderhut, A., Neumann, B., Gregor, A., Juckel, G., Knutson, B., Lehmkuhl, U., Bauer, M., Heinz, A., 2008. Reward anticipation and outcomes in adult males with attentiondeficit/hyperactivity disorder. Neuroimage 39, 966-972.

Sugiura, M., Kawashima, R., Nakagawa, M., Okada, K., Sato, T., Goto, R., Sato, K., Ono, S., Schormann, T., Zilles, K., Fukuda, H., 2000. Correlation between human personality and neural activity in cerebral cortex. Neuroimage 11, 541-546.

Suhara, T., Yasuno, F., Sudo, Y., Yamamoto, M., Inoue, M., Okubo, Y., Suzuki, K., 2001. Dopamine D2 receptors in the insular cortex and the personality trait of novelty seeking. Neuroimage 13, 891-895.

Szerman, N., Peris, L., Mesias, B., Colis, P., Rosa, J., Prieto, A., 2005. Reboxetine for the treatment of patients with Cocaine Dependence Disorder. Hum Psychopharmacol 20, 189192.

Uhl, G. R., 2006. Molecular genetics of addiction vulnerability. NeuroRx 3, 295-301. Urban, N. B., Slifstein, M., Thompson, J. L., Xu, X., Girgis, R. R., Raheja, S., Haney, M., Abi-Dargham, A., 2012. Dopamine release in chronic cannabis users: a [11c]raclopride positron emission tomography study. Biol Psychiatry 71, 677-683.

Van Laere, K., Goffin, K., Bormans, G., Casteels, C., Mortelmans, L., de Hoon, J., Grachev, I., Vandenbulcke, M., Pieters, G., 2009. Relationship of type 1 cannabinoid receptor 
availability in the human brain to novelty-seeking temperament. Arch Gen Psychiatry 66, 196-204.

Van Schuerbeek, P., Baeken, C., De Raedt, R., De Mey, J., Luypaert, R., 2011. Individual differences in local gray and white matter volumes reflect differences in temperament and character: a voxel-based morphometry study in healthy young females. Brain Res 1371, 3242.

Verdejo-Garcia, A., Lawrence, A. J., Clark, L., 2008. Impulsivity as a vulnerability marker for substance-use disorders: review of findings from high-risk research, problem gamblers and genetic association studies. Neurosci Biobehav Rev 32, 777-810.

Volkow, N. D., Chang, L., Wang, G. J., Fowler, J. S., Ding, Y. S., Sedler, M., Logan, J., Franceschi, D., Gatley, J., Hitzemann, R., Gifford, A., Wong, C., Pappas, N., 2001. Low level of brain dopamine D2 receptors in methamphetamine abusers: association with metabolism in the orbitofrontal cortex. Am J Psychiatry 158, 2015-2021.

Volkow, N. D., Fowler, J. S., Wang, G. J., Hitzemann, R., Logan, J., Schlyer, D. J., Dewey, S. L., Wolf, A. P., 1993. Decreased dopamine D2 receptor availability is associated with reduced frontal metabolism in cocaine abusers. Synapse 14, 169-177.

Volkow, N. D., Wang, G. J., Begleiter, H., Porjesz, B., Fowler, J. S., Telang, F., Wong, C., Ma, Y., Logan, J., Goldstein, R., Alexoff, D., Thanos, P. K., 2006. High levels of dopamine D2 receptors in unaffected members of alcoholic families: possible protective factors. Arch Gen Psychiatry 63, 999-1008.

Volkow, N. D., Wang, G. J., Kollins, S. H., Wigal, T. L., Newcorn, J. H., Telang, F., Fowler, J. S., Zhu, W., Logan, J., Ma, Y., Pradhan, K., Wong, C., Swanson, J. M., 2009. Evaluating dopamine reward pathway in ADHD: clinical implications. JAMA 302, 1084-1091.

Volkow, N. D., Wang, G. J., Telang, F., Fowler, J. S., Logan, J., Jayne, M., Ma, Y., Pradhan, K., Wong, C., 2007. Profound decreases in dopamine release in striatum in detoxified alcoholics: possible orbitofrontal involvement. J Neurosci 27, 12700-12706.

Waldorf, D., Reinarman, C., Murphy, S., 1991. Cocaine changes: the experience of using and quitting. Temple University Press, Philadelphia.

Walsh, S. L., Middleton, L. S., Wong, C. J., Nuzzo, P. A., Campbell, C. L., Rush, C. R., Lofwall, M. R., 2012. Atomoxetine does not alter cocaine use in cocaine dependent individuals: A double blind randomized trial. Drug Alcohol Depend. 
Wang, G. J., Smith, L., Volkow, N. D., Telang, F., Logan, J., Tomasi, D., Wong, C. T., Hoffman, W., Jayne, M., Alia-Klein, N., Thanos, P., Fowler, J. S., 2012. Decreased dopamine activity predicts relapse in methamphetamine abusers. Mol Psychiatry 17, 918-925. Wang, G. J., Volkow, N. D., Fowler, J. S., Logan, J., Abumrad, N. N., Hitzemann, R. J., Pappas, N. S., Pascani, K., 1997. Dopamine D2 receptor availability in opiate-dependent subjects before and after naloxone-precipitated withdrawal. Neuropsychopharmacology 16, 174-182.

Whelan, R., Conrod, P. J., Poline, J. B., Lourdusamy, A., Banaschewski, T., Barker, G. J., Bellgrove, M. A., Buchel, C., Byrne, M., Cummins, T. D., Fauth-Buhler, M., Flor, H., Gallinat, J., Heinz, A., Ittermann, B., Mann, K., Martinot, J. L., Lalor, E. C., Lathrop, M., Loth, E., Nees, F., Paus, T., Rietschel, M., Smolka, M. N., Spanagel, R., Stephens, D. N., Struve, M., Thyreau, B., Vollstaedt-Klein, S., Robbins, T. W., Schumann, G., Garavan, H., 2012. Adolescent impulsivity phenotypes characterized by distinct brain networks. Nat Neurosci 15, 920-925.

WHO, 2012. World Drug Report. . World Health Organization http://www.unodc.org/unodc/en/data-and-analysis/WDR-2012.html.

Whohlwill, J. F., 1984. What are sensation seekers seeking? Behavioral and Brain Sciences 7, 453.

Wilbertz, G., van Elst, L. T., Delgado, M. R., Maier, S., Feige, B., Philipsen, A., Blechert, J., 2012. Orbitofrontal reward sensitivity and impulsivity in adult attention deficit hyperactivity disorder. Neuroimage 60, 353-361.

Willuhn, I., Burgeno, L. M., Everitt, B. J., Phillips, P. E., 2012. Hierarchical recruitment of phasic dopamine signaling in the striatum during the progression of cocaine use. Proc Natl Acad Sci U S A 109, 20703-20708.

Winstanley, C. A., Bachtell, R. K., Theobald, D. E., Laali, S., Green, T. A., Kumar, A., Chakravarty, S., Self, D. W., Nestler, E. J., 2009. Increased impulsivity during withdrawal from cocaine self-administration: role for DeltaFosB in the orbitofrontal cortex. Cereb Cortex $19,435-444$.

Wiskerke, J., Schetters, D., van Es, I. E., van Mourik, Y., den Hollander, B. R., Schoffelmeer, A. N., Pattij, T., 2011. mu-Opioid receptors in the nucleus accumbens shell region mediate the effects of amphetamine on inhibitory control but not impulsive choice. J Neurosci 31, $262-272$. 
Wittmann, B. C., Daw, N. D., Seymour, B., Dolan, R. J., 2008. Striatal activity underlies novelty-based choice in humans. Neuron 58, 967-973.

Wong, C. C., Schumann, G., 2008. Review. Genetics of addictions: strategies for addressing heterogeneity and polygenicity of substance use disorders. Philos Trans R Soc Lond B Biol Sci 363, 3213-3222.

Yates, J. R., Marusich, J. A., Gipson, C. D., Beckmann, J. S., Bardo, M. T., 2012. High impulsivity in rats predicts amphetamine conditioned place preference. Pharmacol Biochem Behav 100, 370-376.

Youn, T., Lyoo, I. K., Kim, J. K., Park, H. J., Ha, K. S., Lee, D. S., Abrams, K. Y., Lee, M. C., Kwon, J. S., 2002. Relationship between personality trait and regional cerebral glucose metabolism assessed with positron emission tomography. Biol Psychol 60, 109-120. Yu, R., 2012. Regional white matter volumes correlate with delay discounting. PLoS One 7, e32595.

Zald, D. H., Cowan, R. L., Riccardi, P., Baldwin, R. M., Ansari, M. S., Li, R., Shelby, E. S., Smith, C. E., McHugo, M., Kessler, R. M., 2008. Midbrain dopamine receptor availability is inversely associated with novelty-seeking traits in humans. J Neurosci 28, 14372-14378. Zukerman, M., 1979. Sensation seeking: beyond the optimal level of arousal. Lawrence Erlbaum Associates, Hillsdale. 
Figure 1: Summary of the key imaging biomarkers associated with impulsivity, sensation/novelty-seeking and drug addiction. For all images red/yellow indicates higher, while blue indicates lower values compared with healthy controls. For simplicity, regions of interest combine (i) dorsal and ventral striatum (D/VS), and (ii) medial and lateral regions of prefrontal cortex (M/LPFC). Impulsivity and sensation-seeking are associated with increased reward reactivity in the D/VS. However, in addicts, reward reactivity is reduced in these regions. Sensation-seekers demonstrate enhanced activity in M/LPFC. However, both impulsive individuals and drug addicts show broad-ranging abnormalities in structural integrity and volume of M/LPFC, anterior cingulate cortex (ACC), and orbitofrontal cortex (OFC). These markers closely associate with reduced metabolism in these regions with the exception of the OFC in impulsive individuals. By contrast, sensation-seekers show increased volume in posterior cingulate cortex (PCC) and increased metabolism in M/LPFC but not the OFC. D2/D3 receptor availability is decreased in the D/VS of all three groups. Collectively, these results suggest an involvement of reduced striatal D2/D3 availability in the general risk for addiction. However, dissociable alterations are observed in brain morphology and metabolism for impulsivity, sensation/novelty-seeking, and addiction, and these may reflect differential contributions of impulsivity and sensation/novelty-seeking to different stages of addiction. By contrast, findings in addicts of reduced striatal reward reactivity and orbitofrontal metabolism compared with impulsive and sensation-seeking individuals appear to reflect the impact of repeated drug bingeing and withdrawal. 
Click here to download high resolution image ACCEPTED MANUSCRIPT

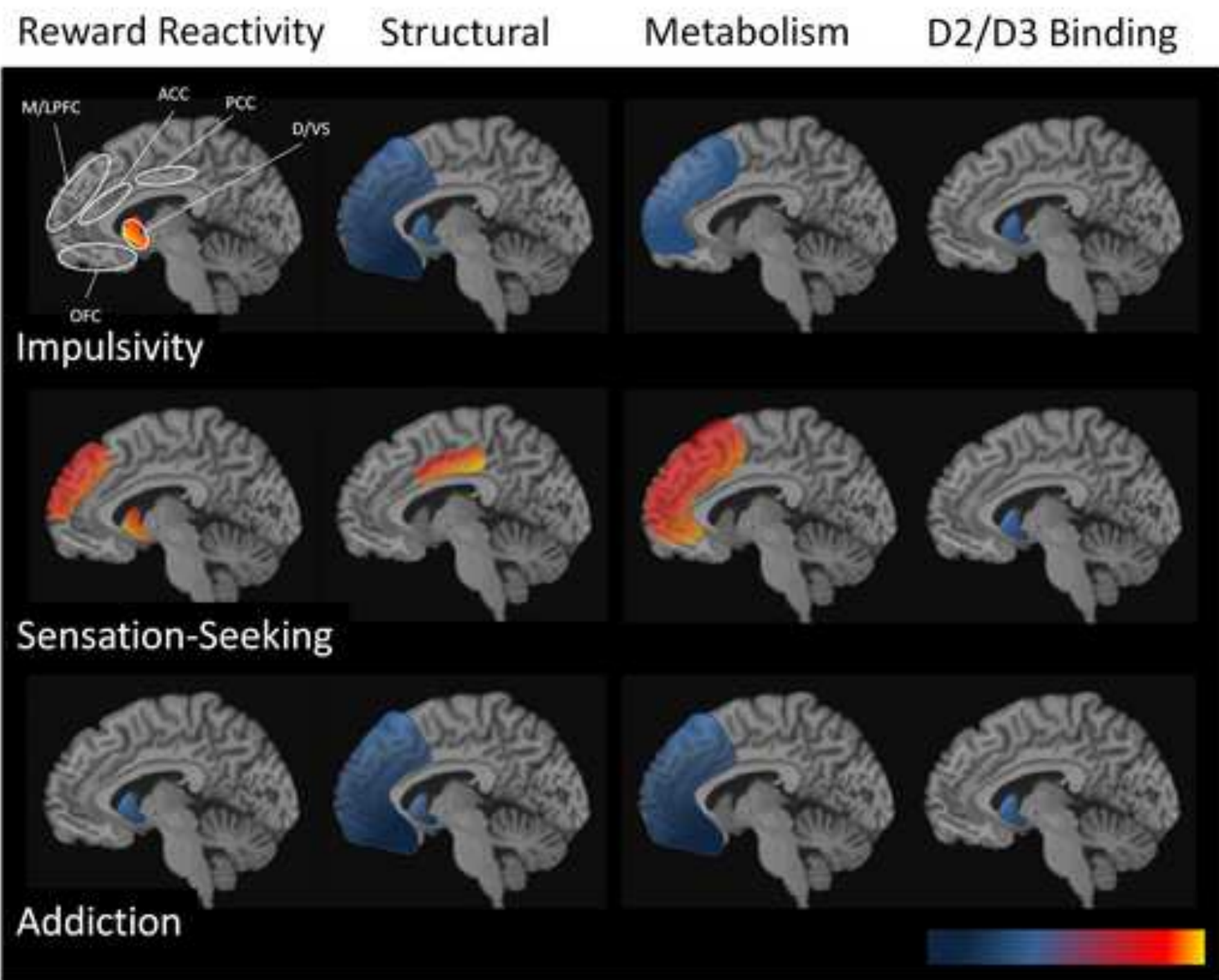




\section{University Library}

\section{- M M N E R VA A gateway to Melbourne's research publications}

Minerva Access is the Institutional Repository of The University of Melbourne

Author/s:

Jupp, B;Dalley, JW

Title:

Behavioral endophenotypes of drug addiction: Etiological insights from neuroimaging studies

Date:

2014-01-01

\section{Citation:}

Jupp, B. \& Dalley, J. W. (2014). Behavioral endophenotypes of drug addiction: Etiological insights from neuroimaging studies. NEUROPHARMACOLOGY, 76 (PART B), pp.487-497. https://doi.org/10.1016/j.neuropharm.2013.05.041.

Publication Status:

Accepted manuscript

Persistent Link:

http://hdl.handle.net/11343/41844 